\title{
Low hospital admission rates for respiratory diseases in children
}

\author{
Johannes HJM Uijen ${ }^{1}$, François G Schellevis², Patrick JE Bindels', Sten P Willemsen', \\ Johannes $C$ van der Wouden ${ }^{*}$
}

\begin{abstract}
Background: Population-based data on hospital admissions for children aged 0-17 years concerning all respiratory diseases are scarce. This study examined hospital admissions in relation to the preceding consultations in general practice in this age group.

Methods: Data on children aged 0-17 years with respiratory diseases included in the Second Dutch National Survey of General Practice (DNSGP-2) were linked to all hospital admissions in the Dutch National Medical Registration. Admission rates for respiratory diseases were calculated. Data were analysed using multivariate logistic regression.

Results: Of all 79,272 children within the DNSGP-2, 1.8\% were admitted to hospital for any respiratory diagnosis. The highest admission rates per 1000 children were for chronic disease of tonsils and adenoids (12.9); pneumonia and influenza (0.97); and asthma (0.92). Children aged 0-4 years and boys were admitted more frequently. Of children with asthma, $2.3 \%$ were admitted for respiratory diseases. For asthma, admission rates varied by urbanisation level: $0.47 / 1000$ children/year in cities with $\leq 30,000$ inhabitants, 1.12 for cities with $\geq 50,000$ inhabitants, and 1.73 for the three largest cities $(p=0.002)$. Multivariate logistic regression showed that within two weeks after a GP consultation, younger age (OR $0.81,95 \% \mathrm{Cl} 0.76-0.88)$ and more severe respiratory diseases (5.55, 95\% Cl 2.99-8.11) predicted hospital admission.
\end{abstract}

Conclusions: Children in the general population with respiratory diseases (especially asthma) had very low hospital admission rates. In urban regions children were more frequently admitted due to respiratory morbidity. For effectiveness studies in a primary care setting, hospital admission rates should not be used as quality end-point.

\section{Background}

Respiratory symptoms account for about $25 \%$ of consultations for children in general practice [1]. Respiratory tract infections are the leading cause of childhood hospital admission [2-4], which is often an unpleasant experience for the child and their parents. Data on hospital admissions for children aged 0-17 years concerning the total spectrum of respiratory diseases are scarce. Generally, data on a specific age group (e.g. preschool children) or on a specific respiratory disease (e.g. asthma) are reported [5-7]. Most admission data are hospital based [8], but the catchment area and hence the denominator for calculating these hospital admission

\footnotetext{
* Correspondence: j.vanderwouden@erasmusmc.nl

'Department of General Practice, Erasmus MC University Medical Center, Rotterdam, the Netherlands

Full list of author information is available at the end of the article
}

rates is often not known. Primary care data linked with hospital admission registration data can be useful for allocating resources, to plan hospital care, to predict admissions for children from general practice, and studies conducted in primary and specialised care might benefit from these data.

In recent decades various factors have influenced morbidity patterns in children with respiratory diseases. For example, the introduction of inhalation therapy with bronchodilators and corticosteroids for the treatment of asthma, guidelines recommending a restrictive policy towards prescribing antibiotics for respiratory symptoms $[9,10]$, vaccination programmes against respiratory diseases (e.g. influenza and Streptococcus pneumoniae), and demographic changes such as population growth and the influx of ethnic minorities $[11,12]$. Therefore, this study investigated morbidity and hospital admission 
patterns for respiratory diseases in children at the turn of this century. Linking the data of a large national survey of general practice with admission data from the national medical registration enabled us to determine hospital admission rates and risk factors for hospital admission for children aged 0-17 years who presented with various respiratory diseases in general practice.

\section{Methods}

Data were derived from the most recent nationwide study, the Second Dutch National Survey of General Practice (DNSGP-2) conducted in 2001 by the Netherlands Institute for Health Services Research (NIVEL) [13]. The Dutch National Medical Registration, maintained by the Dutch Centre for Health Care Information, was asked to provide data on all admissions of all children included in the DNSGP-2 database.

\section{Second Dutch National Survey of General Practice (DNSGP-2)}

During the one-year registration period (i.e. 2001), 195 general practitioners (GPs) in 104 practices throughout the Netherlands participated in data collection. In the Netherlands, general practices have a fixed patient list, all inhabitants are listed in a general practice, and GPs have a gate-keeping role for specialized care. The patients enlisted in the participating practices were comparable to the general Dutch population with respect to age, gender, and type of healthcare insurance.

Data on all physician-patient contacts, prescriptions and referrals during the 12 months were extracted from the electronic medical records of all children aged 0-17 years listed in the participating practices. All diagnoses were coded using the International Classification of Primary Care (ICPC) [14]. For the current analysis, data from 14 of the 104 practices were excluded because data were incomplete due to suboptimal recording quality. Therefore, the study included 90 practices with a total of 79,272 children.

\section{Dutch National Medical Registration}

The National Medical Registration contains information on all admissions (225,000 per annum) to all (teaching and general) hospitals in the Netherlands. Patient characteristics such as birth date, gender, postal code, and diagnostic and therapeutic interventions are registered. Admission and discharge dates, and cause of death during hospital admission are also registered. All diagnoses in the National Medical Registration are coded by trained coding clerks using the International Classification of Diseases (ICD-9) [15]. Admissions for respiratory diseases are defined according to the ICD-9 (see Additional file 1: Appendix). For the present study, we focussed on the principal diagnoses, and categorized these diagnoses into seven groups: nasopharyngitis, laryngitis and sinusitis (ICD 460-464, 472, 473, 476), acute upper respiratory infections (ICD 465), acute bronchitis and bronchiolitis (ICD 466), chronic disease of tonsil and adenoids, peritonsillar abscess (ICD 474-475), pneumonia and influenza (ICD 480-487), asthma (ICD 490496), and other diseases of respiratory system (ICD 470, $471,477,478,488,507,510-519)$. In case of multiple admissions we only included the first admission during the registration period.

\section{Linking National Medical Registration to DNSGP-2}

Patients in both databases were linked through the combination of date of birth, sex and the four-digit postal code [16].

The DNSGP-2 included 79,272 children aged 0-17 years. During the 2001 registration period, for these children a diagnosis of a respiratory disease was registered 20,173 times by the GPs during a first contact of an episode. During the same period, the National Medical Registration contained 1,518 admissions for all respiratory diagnoses for the 1,412 children in the DNSGP-2. Figure 1 shows the selection process for the study population.

For the identification of determinants predicting hospital admission for an acute respiratory illness, we assumed that hospital admissions for ear, nose or throat (ENT) problems (ICD 474 and 475) were planned hospital admissions for surgical interventions. These planned ENT admissions were excluded.

\section{Characteristics of patients and GPs}

The following characteristics were derived from the computerized patient files of DNSGP-2: age and sex of the child; season in which the GP consultation occurred (October-March versus April-September); severity of the respiratory complaint or disease [severe (R02 Shortness of breath/dyspnoea; R76 Tonsil abscess; R77 Laryngitis/tracheitis acute; R78 Acute bronchitis/ bronchiolitis; R81 Pneumonia; R82 Pleurisy/pleural effusion; R96 Asthma) versus not-severe (all other diagnoses)]; single-handed practice, or not. The degree of urbanisation of the patients' living area was derived from the general practice postal code and categorized into four classes: 'less than 30,000 inhabitants', '30,00050,000 inhabitants', 'more than 50,000 inhabitants', and 'the three largest Dutch cities Amsterdam, Rotterdam and The Hague'.

\section{Statistical analysis}

Data on all hospital admissions for respiratory diagnoses in children aged 0-17 years were analysed. Admission rates for respiratory diseases per 1,000 children were calculated using the population size in the denominator 
All children in DNSGP-2 practices

$\mathrm{n}=79,272$ children

(with 20,173 respiratory contacts)

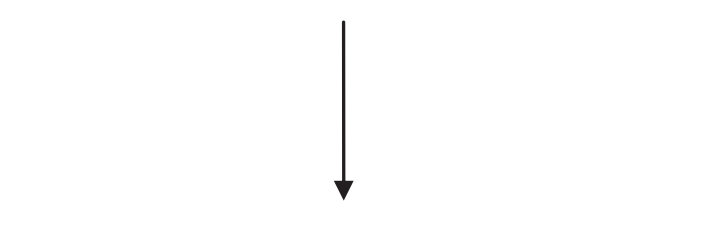

National Medical Registration

All children with respiratory admission

diagnosis from DNSGP-2 practices

$\mathrm{n}=1,412$ children

(with 1,518 respiratory admissions)

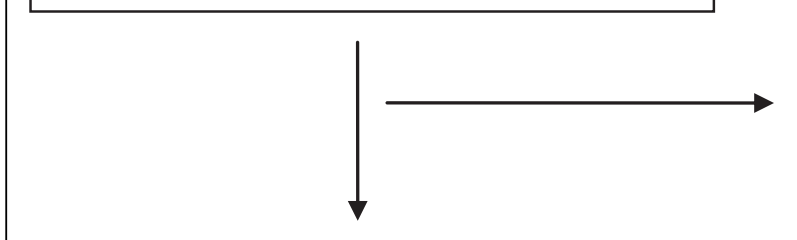

Children with planned admission for a surgical intervention of ear, nose or throat (ENT)

$\mathrm{n}=1,098$ children

Children with admission for acute respiratory disease without planned ENT procedures

$$
\mathrm{n}=314 \text { children }
$$

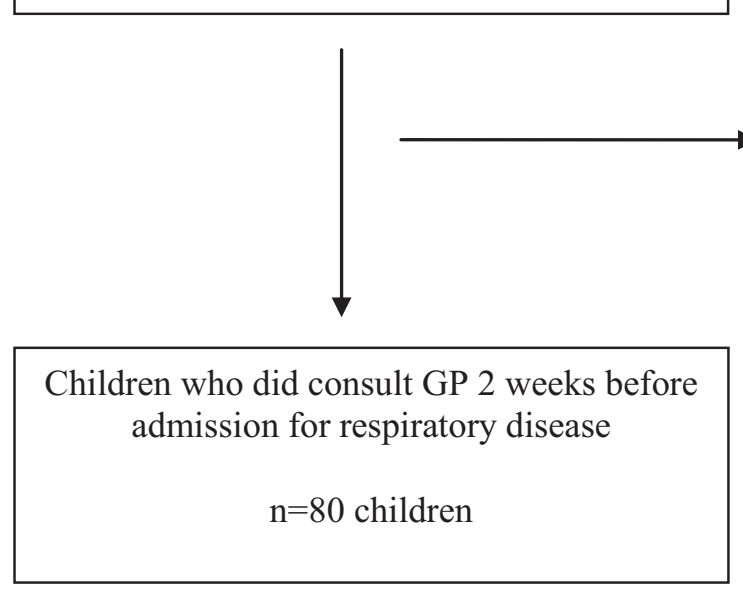

Children who did not consult GP 2 weeks before admission for respiratory disease

$$
\mathrm{n}=234 \text { children }
$$

Figure 1 Selection of the study population (aged 0-17 years) from the Second Dutch National Survey of General Practice (DNSGP-2) matched with hospital admissions for respiratory illness (Dutch National Medical Registration).

and the number of admissions as numerator. Differences in admission rates were tested with Chi-square tests (significance level $\mathrm{p}=0.05$ ). To model the probability to be admitted, after a GP contact within two weeks before admission, a logistic regression model with a random practice effect was estimated and multivariate odds ratios (OR) were calculated. It was not possible to include a random effect for an individual besides the practice-specific effect. However, fitting slightly simplified models showed that the omission of this determinant had only a negligible effect on the ORs and their confidence intervals. 


\section{Results}

\section{General characteristics}

During the one-year registration period, of the 79,272 children aged $0-17$ years 1,412 (1.8\%) were admitted to hospital for any respiratory diagnosis. Of these 1,412 children, $54.4 \%$ was male. Overall, $63.5 \%$ was aged $0-4$ years, $24.8 \% 5-9$ years, and $11.7 \%$ aged $10-17$ years.

In total, 11\% of the GP consultations were registered outside normal office hours (between 8 AM and 17 PM) or in the weekend.

Of all admitted children, $38.2 \%$ lived in an urban community of $\leq 30,000$ inhabitants, $19.2 \%$ in a community of $30,000-50,000,35 \%$ in a community of $\geq 50,000$ inhabitants (excluding the 3 largest Dutch cities), and $7.6 \%$ lived in the three largest cities.

During the registration period, $94 \%$ of the 1,412 children were admitted once for a respiratory diagnosis, 61 children were admitted two times, 14 children three times, 3 children four times, and 2 children were admitted five times (a total of 1,518 admissions).

\section{Distribution of children and admissions by respiratory diagnosis group}

Table 1 shows that the majority of children (73\%) were admitted with a chronic disease of tonsils, adenoids and/or peritonsillar abscesses. Of the remaining six respiratory diagnosis groups, each group accounted for about $5 \%$ of all admissions. Among these, pneumonia and influenza (5.7\%) and asthma (6.7\%) were the most frequent reasons for admission.

The diagnostic categories 'chronic diseases of tonsils, adenoids and peritonsillar abscess', 'nasopharyngitis, laryngitis and sinusitis', and the remainder group 'other respiratory diagnoses' had the most admissions and discharges within 24 hours $(87 \%, 48 \%$ and $31 \%$, respectively). Most children with 'acute upper respiratory infections', 'pneumonia and influenza', 'acute bronchitis and bronchiolitis', and 'asthma' had a hospital stay of $1-7$ days $(74 \%, 70 \%, 71 \%$ and $70 \%$, respectively). A longer hospital stay of 8-30 days was seen in children with 'acute bronchitis and bronchiolitis', 'pneumonia and influenza' and 'asthma' (30\%, 26\%, 23\%, respectively).

\section{Admission rates by diagnosis}

The highest admission rates per 1000 children were for 'chronic disease of tonsils and adenoids', 'pneumonia and influenza', and 'asthma' (12.9, 0.97, and 0.92, respectively) (Table 2). Boys were admitted more frequently than girls. In all groups, admission rates were significantly higher among children aged 0-4 years (39/1000) than in older age groups (5-9 years: $16 / 1000 ; 10-17$ years: 4.8/1000).

Children with 'acute upper respiratory infections', 'pneumonia and influenza' and 'asthma' were significantly more frequently admitted to hospital when living in a more urbanised region. In total, 3,417 children in the DNSGP-2 database consulted their GP for asthma and $77(2.3 \%)$ of these children were admitted to hospital. The admission rate for asthma in rural areas was 0.47 per 1000 children per year; in suburban areas it was 1.27; in urban areas it was 1.12; and for the 3 largest cities the admission rate was $1.73(\mathrm{p}=0.002)$.

Of all children admitted with a respiratory diagnosis, one died in hospital. This was an 8-month-old child admitted with pneumonia (ICD 486) who had a severe underlying neuromuscular disease.

Of the 1,412 children, 323 (23\%) children had 396 admissions for an ICD diagnosis that we considered not to be planned (Figure 1).

Table 1 Number of admissions and duration of hospital stay per diagnosis for children aged 0-17 years.

\begin{tabular}{|c|c|c|c|c|c|c|}
\hline \multirow[t]{2}{*}{ ICD codes* } & \multirow[t]{2}{*}{ Diagnoses } & \multirow[t]{2}{*}{$\begin{array}{r}\text { No. of children } \\
(\%)\end{array}$} & \multirow[t]{2}{*}{$\begin{array}{r}\text { No. of } \\
\text { admissions (\%) }\end{array}$} & \multicolumn{3}{|c|}{$\begin{array}{r}\text { Duration of hospital } \\
\text { stay in\% }\end{array}$} \\
\hline & & & & $\begin{array}{r}\leq 24 \\
\text { hours }\end{array}$ & $\begin{array}{r}2-7 \\
\text { days }\end{array}$ & $\begin{array}{r}\geq 8 \\
\text { days }\end{array}$ \\
\hline $460-464,472,473,476$ & $\begin{array}{l}\text { (Acute + chronic) nasopharyngitis, laryngitis, } \\
\text { tracheitis, sinusitis }\end{array}$ & $62(4.1)$ & $66(4.2)$ & 48 & 50 & 2 \\
\hline 465 & Acute upper respiratory infections & $58(3.9)$ & $60(4.0)$ & 10 & 74 & 16 \\
\hline 466 & Acute bronchitis and bronchiolitis & $50(3.3)$ & $51(3.4)$ & 0 & 70 & 30 \\
\hline $474-475$ & $\begin{array}{l}\text { Chronic disease of tonsils and adenoids, } \\
\text { peritonsillar abscess }\end{array}$ & $1098(73.2)$ & $1075(70.8)$ & 87 & 12 & 1 \\
\hline $480-487$ & Pneumonia and influenza & $80(5.3)$ & $87(5.7)$ & 3 & 71 & 26 \\
\hline $490-496$ & Asthma & 77 (5.2) & $101(6.7)$ & 7 & 70 & 23 \\
\hline $\begin{array}{l}470,471,477,478,488,507, \\
510-519\end{array}$ & Other diseases of respiratory system & $75(5.0)$ & $78(5.2)$ & 31 & 57 & 12 \\
\hline Total & & $1500(100) \#$ & $1518(100)$ & 26 & 58 & 16 \\
\hline
\end{tabular}


Table 2 Admission rates for respiratory diseases per 1000 children.

\begin{tabular}{|c|c|c|c|c|c|c|c|c|c|c|c|c|c|}
\hline \multirow[b]{2}{*}{ Diseases (ICD codes) } & \multirow[t]{2}{*}{ All } & \multicolumn{2}{|c|}{ Gender } & \multicolumn{5}{|c|}{ Age } & \multicolumn{5}{|c|}{ Urbanisation } \\
\hline & & Male & Female & $\begin{array}{l}\mathrm{p}- \\
\text { value }\end{array}$ & $\begin{array}{l}0-4 \\
\text { years }\end{array}$ & $\begin{array}{l}5-9 \\
\text { years }\end{array}$ & $\begin{array}{l}10- \\
17 \\
\text { years }\end{array}$ & $\begin{array}{c}\mathrm{p}- \\
\text { value }\end{array}$ & $<30,000$ & $\begin{array}{l}30,000 \\
- \\
50,000\end{array}$ & $\begin{array}{l}>50,000 \text { excl. } \\
\text { the } 3 \text { largest } \\
\text { cities }\end{array}$ & $\begin{array}{l}3 \\
\text { largest } \\
\text { cities }\end{array}$ & $\begin{array}{c}\mathrm{p}- \\
\text { value }\end{array}$ \\
\hline $\begin{array}{l}\text { Nasopharyngitis, laryngitis, } \\
\text { sinusitis }(460-464,472,473,476)\end{array}$ & 0.75 & 0.71 & 0.80 & 0.64 & 1.33 & 0.44 & 0.56 & $<0.01$ & 0.68 & 0.96 & 0.78 & 0.52 & 0.66 \\
\hline $\begin{array}{l}\text { Acute upper respiratory } \\
\text { infections (465) }\end{array}$ & 0.71 & 0.97 & 0.43 & $\begin{array}{r}< \\
0.01\end{array}$ & 2.17 & 0.13 & 0.08 & $<0.01$ & 0.59 & 0.32 & 0.93 & 1.38 & 0.02 \\
\hline $\begin{array}{l}\text { Acute bronchitis, bronchiolitis } \\
\text { (466) }\end{array}$ & 0.61 & 0.59 & 0.63 & 0.85 & 2.00 & 0.09 & 0 & $<0.01$ & 0.47 & 0.57 & 0.71 & 1.04 & 0.34 \\
\hline $\begin{array}{l}\text { Chronic disease of tonsil and } \\
\text { adenoids, peritonsillar abscess } \\
(474-475)\end{array}$ & 12.86 & 12.96 & 12.75 & 0.79 & 26.90 & 13.84 & 2.75 & $<0.01$ & 12.55 & 13.13 & 13.34 & 11.74 & 0.70 \\
\hline $\begin{array}{l}\text { Pneumonia and influenza (480- } \\
\text { 487) }\end{array}$ & 0.97 & 1.28 & 0.65 & $\begin{array}{r}< \\
0.01\end{array}$ & 2.79 & 0.22 & 0.22 & $<0.01$ & 0.71 & 0.57 & 1.46 & 1.38 & 0.01 \\
\hline Asthma (490-496) & 0.92 & 1.28 & 0.55 & $\begin{array}{r}< \\
0.01\end{array}$ & 2.46 & 0.44 & 0.20 & $<0.01$ & 0.47 & 1.27 & 1.12 & 1.73 & $\begin{aligned}< \\
0.01\end{aligned}$ \\
\hline $\begin{array}{l}\text { Other diseases of respiratory } \\
\text { system }(470,471,477,478,488, \\
507,510-519)\end{array}$ & 0.90 & 1.06 & 0.73 & 0.10 & 1.29 & 0.40 & 0.96 & $<0.01$ & 0.82 & 0.57 & 1.12 & 1.21 & 0.24 \\
\hline TOTAL & 17.72 & 18.85 & 16.54 & 0.03 & 38.94 & 15.56 & 4.77 & $<0.01$ & 16.29 & 17.39 & 19.46 & 19.00 & 0.08 \\
\hline
\end{tabular}

\section{Distribution of diagnoses and GP consultation}

Of the 80 children who consulted their GP two weeks before hospital admission, a higher percentage of children were admitted with 'nasopharyngitis, laryngitis, tracheitis, sinusitis', 'bronchitis and bronchiolitis' and 'pneumonia and influenza' compared with children who did not consult the GP (Table 3). In the group of 234 children who did not consult the GP two weeks before hospital admission, two differences showed significance. A lower percentage of children in this group were admitted with acute bronchitis and bronchiolitis $(\mathrm{p}=$ 0.02 ) and a higher percentage of children were admitted with asthma $(\mathrm{p}<0.001)$.

\section{Determinants predicting hospital admission for} respiratory diseases

Table 4 shows the adjusted ORs obtained from the logistic regression model. The multivariate logistic regression showed that younger age and more severe respiratory diseases predict a hospital admission in the two weeks after GP consultation. None of the other included determinants had an independent effect on hospital admission.

\section{Discussion}

In this nationally representative study population, admission to hospital for a respiratory diagnosis occurred in only $1.8 \%$ of children. Children aged $<4$ years with respiratory diagnoses were admitted more often. Admission rates for acute respiratory tract infections, pneumonia and influenza, and asthma were higher in urban regions than in rural areas. Admissions for asthma were not common, i.e. about $0.1 \%$ of all children, and $2.3 \%$ of all children who consulted their GP with asthma. Many of the admissions were planned (77\%), mostly for ENT procedures. Children with upper

Table 3 Distribution of diagnoses for all children with admission for acute respiratory disease without ENT procedures ( $n=314$ ), for children who did consult GP two weeks before admission for respiratory disease $(n=80)$ and for children who did not consult GP two weeks before admission for respiratory disease $(\mathbf{n}=\mathbf{2 3 4})$.

\begin{tabular}{|c|c|c|c|c|}
\hline ICD codes & Diagnoses & $\begin{array}{r}\text { All children (\%) } \\
(\mathrm{n}=314)\end{array}$ & $\begin{array}{r}\text { Children who consulted } \\
\text { GP }(\%)(n=80)\end{array}$ & $\begin{array}{r}\text { Children who did not consult } \\
\text { GP }(\%)(n=234)\end{array}$ \\
\hline $460-464,472,473,476$ & $\begin{array}{l}\text { (Acute + chronic) nasopharyngitis, } \\
\text { laryngitis, tracheitis, sinusitis }\end{array}$ & $29(9.2)$ & $10(12.5)$ & $19(8.1)$ \\
\hline 465 & Acute upper respiratory infections & $55(17.5)$ & $15(18.8)$ & $40(17.1)$ \\
\hline 466 & Acute bronchitis and bronchiolitis & 49 (15.6) & $19(23.8)$ & $30(12.8)$ \\
\hline $480-487$ & Pneumonia and influenza & $78(24.8)$ & $23(28.7)$ & $55(23.5)$ \\
\hline $490-496$ & Asthma & $73(23.3)$ & $6(7.5)$ & $67(28.6)$ \\
\hline $\begin{array}{l}470,471,477,478,488 \\
507,510-519\end{array}$ & Other diseases of respiratory system & $30(9.6)$ & $7(8.7)$ & $23(9.7)$ \\
\hline
\end{tabular}


Table 4 Relation between child and GP determinants and hospital admission for respiratory disease ( $n=95 \mathrm{GP}$ contacts two weeks before admission).

\begin{tabular}{|c|c|c|}
\hline & $\begin{array}{l}\text { Relative probability of hospital admission } \\
\text { within } 2 \text { weeks after GP consultation } \\
(\mathrm{n}=95) \\
\text { OR }(95 \% \mathrm{Cl})\end{array}$ & $\begin{array}{l}\mathrm{p}- \\
\text { value }\end{array}$ \\
\hline $\begin{array}{l}\text { Age of child } \\
\text { (years) }\end{array}$ & $0.81(0.76-0.88)$ & $<0.001$ \\
\hline \multicolumn{3}{|l|}{ Sex: } \\
\hline Boy & $1.14(0.63-1.66)$ & 0.55 \\
\hline Girl & (ref) & \\
\hline \multicolumn{3}{|l|}{ Season: } \\
\hline $\begin{array}{l}\text { October- } \\
\text { March }\end{array}$ & $1.18(0.64-1.73)$ & 0.56 \\
\hline $\begin{array}{l}\text { April- } \\
\text { September }\end{array}$ & (ref) & \\
\hline \multicolumn{3}{|l|}{ Severity: } \\
\hline severe & $5.55(2.99-8.11)$ & $<0.001$ \\
\hline not severe & (ref) & \\
\hline \multicolumn{3}{|l|}{ Urbanisation: } \\
\hline rural & $0.96(0.40-1.52)$ & 0.89 \\
\hline suburban & $0.92(0.20-1.64)$ & 0.84 \\
\hline urban & (ref) & \\
\hline \multicolumn{3}{|l|}{ Practice: } \\
\hline $\begin{array}{l}\text { not single- } \\
\text { handed }\end{array}$ & $0.75(0.34-1.16)$ & 0.30 \\
\hline $\begin{array}{l}\text { single- } \\
\text { handed }\end{array}$ & (ref) & \\
\hline
\end{tabular}

Multivariate logistic regression analysis.

respiratory infections, pharyngitis, sinusitis, bronchitis and pneumonia consulted their GP relatively more often in the two weeks before admission. In contrast, children with asthma and other diseases consulted their GP less often before admission. Younger age and a more severe respiratory disease predicted hospital admission in the two weeks after the GP consultation.

The major strength of this study is the use of unique data from a large national survey and the linking of these data to the Dutch National Medical Registration. The study population allowed to calculate admission rates for all respiratory diseases. Characteristics of the study patients are comparable to the general Dutch population, and the GP sample is comparable to the national GP population [17]. Single-handed practices were somewhat underrepresented; however, because this item is not related to study outcome it is not considered an important limitation. The results can be assumed to represent regular primary care and consultation behaviour in the Netherlands.

About 11\% of the GP consultations were registered outside normal office hours or in the weekend. Although this may entail some underrepresentation, we don't believe this limits generalizability.
We could not test the assumption that all admissions for ICD codes 474 and 475 were planned. However, over $99 \%$ of these admissions were for ICD code 474 , which concerns chronic disease of tonsils and adenoids. In the Netherlands, the vast majority of admissions under this diagnosis is due to planned (adeno) tonsillectomy.

$2.3 \%$ of all children who consulted their GP for asthma were admitted to hospital. The denominator of this proportion underestimates the true number of asthmatic children since not all asthmatic children (mainly children suffering from intermittent asthma) may have consulted their GP within the study period.

Although the data we used are several years old, we do not believe this is a major limitation. The outcome (low admission rates) would not differ greatly when more recent data would have been available. We used the most recent nationwide study for answering our research question.

The present study provides insight into the large differences in disease profiles for children treated in general practice or in hospital. For example, in general practice 5\% of the presented respiratory problems concern pneumonia [18]. In contrast, $25 \%$ of the children with a respiratory problem were admitted to hospital with pneumonia (Table 3 ). On the other hand, $17 \%$ of children admitted to hospital suffered from acute upper respiratory infections compared with $32 \%$ of the children in general practice. The relative contribution of asthma was about $22 \%$ in both general practice and in hospital [18]. The considerable difference in disease presentation of children consulting GPs or hospital physicians was reported by Hodgkin in his classic work dating from 1978 [19].

Of the 314 children with an unplanned admission to hospital, only $25 \%$ attended general practice with respiratory complaints two weeks before admission. Of the 234 (75\%) children who did not consult the GP two weeks before admission, $45 \%$ did not visit their general practice at any time during the one-year registration period. We assume that these children were already receiving specialised care.

Children with acute upper respiratory infections, pneumonia, influenza and asthma were admitted to a hospital significantly more often when living in an urbanised region. This might be due to greater air pollution in urban regions. The impact of air pollution on respiratory admissions and asthma has been reported in Canada and Italy [20,21]. Another explanation could be the availability of hospitals in urban regions.

Gender and age differences are common in hospitalization rates for respiratory diseases $[22,23]$. In the present study we also found that younger children and boys were admitted more often than older children and girls. 
The finding that children with more severe illness are more likely to get admitted, is not surprising. More surprising is that no other determinants turned out to be related to admission.

The present study found very low admission rates for respiratory diseases, especially for asthma. Hospital admission is often used as quality parameter [24,25]. The low admission rates in our study show that it may be necessary to reconsider the use of hospital admission as a quality parameter for asthma treatment, and that for effectiveness studies in primary care settings admission rates should no longer be used as a quality endpoint.

\section{Conclusions}

Children in the general population with respiratory complaints/diseases had very low hospital admission rates. There is a large difference in the scope of work of GPs and specialists in relation to respiratory diseases in children. In urban regions children were more frequently admitted with upper respiratory infections, pneumonia, influenza and asthma. Finally, we suggest that for effectiveness studies in a primary care setting the hospital admission rate should not be used as quality end-point.

\section{Additional material}

Additional file 1: Appendix ICD-9 codes. ICD-9 codes used to select all children admitted with a respiratory diagnosis.

\section{Author details}

${ }^{1}$ Department of General Practice, Erasmus MC University Medical Center, Rotterdam, the Netherlands. ${ }^{2}$ NIVEL, Netherlands Institute for Health Services Research, Utrecht, the Netherlands; and Department of General Practice EMGO Institute, VU University Medical Center, Amsterdam, the Netherlands.

\section{Authors' contributions}

JHJMU participated in the study design, was involved in the statistical analysis, and drafted the manuscript. FGS participated in the study design and revised the manuscript critically. PJEB participated in the study design and revised the manuscript critically.

SPW performed statistical analyses and helped to draft the manuscript. JCvdW participated in the study design, was involved in the statistical analysis, and revised the manuscript critically. All authors read and approved the final manuscript.

\section{Authors' information}

JHJMU: MD, GP., FGS: MD, PhD, professor of general practice., PJEB: MD, PhD, professor of general practice., SPW: statistician., JCvdW: PhD, senior lecturer.

\section{Competing interests}

The authors declare that they have no competing interests.

Received: 14 April 2010 Accepted: 9 October 2010

Published: 9 October 2010
References

1. Otters HB, van der Wouden JC, Schellevis FG, van Suijlekom-Smit LW, Koes BW: Changing morbidity patterns in children in Dutch general practice: 1987-2001. Eur J Gen Pract 2005, 11:17-22.

2. Carville KS, Lehmann D, Hall G, Moore H, Richmond P, de Klerk N, Burgner D: Infection is the major component of the disease burden in aboriginal and non-aboriginal Australian children: a population-based study. Pediatr Infect Dis J 2007, 26:210-6.

3. Yorita KL, Holman RC, Sejvar JJ, Steiner CA, Schonberger LB: Infectious disease hospitalizations among infants in the United States. Pediatrics 2008, 121:244-52.

4. Diaz-Caneja A, Gledhill J, Weaver T, Nadel S, Garralda E: A Child's admission to hospital: a qualitative study examining the experiences of parents. Intensive Care Med 2005, 31:1248-54

5. Anderson HR, Gupta R, Strachnan DP, Limb ES: 50 years of asthma: UK trends from 1955 to 2004. Thorax 2007, 62:85-90.

6. Pascal L, Fuhrman C, Durif L, Nicolau J, Charpin D, Dujols P, Delmas MC: Trends in hospital admissions for asthma in France, 1998-2002. Rev Mal Respir 2007, 24:581-90.

7. Wennergren G, Strannegard I: Asthma hospitalizations continue to decrease in schoolchildren but hospitalization rates for wheezing illnesses remain high in young children. Acta Paediatr 2002, 91:1239-45.

8. Rasmussen F, Taylor DR, Cowan JO, Greene JM, Herbison GP, Sears MR: Risk factors for hospital admission for asthma from childhood to young adulthood: A longitudinal population study. J Allergy Clin Immunol 2002, 110:220-7

9. Global Strategy for Asthma Management and Prevention. Global Initiative for asthma (GINA) 2007 [http://ginasthma.org].

10. Shields MD, Bush A, Everard ML, McKenzie S, Primhak R: Recommendations for the assessment and management of cough in children. Thorax 2008, 63:1-15.

11. Conyn-van Spaendonck MA, Veldhuijsen IK, Suikerbuijk AW, Hirasing RA: Significant decline of the number of invasive Haemophilus influenzae infections in the first 4 years after introduction of vaccination against $\mathrm{H}$. Influenzae type B in children (in Dutch). Ned Tijdschr Geneeskd 2000, 144:1069-73.

12. Bruijnzeels MA, van der Wouden JC, Foets M: General practice consultation in childhood in the Netherlands: sociodemographic variation. J Epidemiol Community Health 1995, 49:532-3.

13. Westert GP, Schellevis FG, de Bakker DH, Groenewegen PP, Bensing JM, van der Zee J: Monitoring health inequalities through general practice: the Second Dutch National Survey of General Practice. Eur J Public Health 2005, 15:59-65.

14. Anonymous: ICPC-2: International Classification of Primary care. Oxford: World Organization of National Colleges, Academies, and Academic Associations of General Practitioners/Family Physicians 1998.

15. Anonymous: International Classification of Diseases, Ninth Revision. Clinical Modification (ICD-9). Ann Arbor: Commission on Professional and Hospital Activities 1979

16. Struijs NJ, Baan CA, Slobbe LCJ, Droomers M, Westert GP: Koppeling van anonieme huisartsgegevens aan ziekenhuisregistraties. [Linking anonymized GP data to hospital registration]. Bilthoven: RIVM 2004

17. Schellevis FG, Westert GP, de Bakker DH, Groenewegen PP: Tweede nationale studie naar ziekten en verrichtingen in de huisartspraktijk. Vraagstellingen en methoden [the Second Dutch National Survey of General Practice. Objectives and methods]. Utrecht/Bilthoven: NIVEL/RIVM 2004.

18. Van der Linden MW, van Suijlekom-Smit LWA, Schellevis FG, van der Wouden JC: Tweede Nationale Studie naar ziekten en verrichtingen in de huisartspraktijk: het kind in de huisartspraktijk. Utrecht, NIVEL 2005.

19. Hodgkin K: Towards earlier diagnosis in primary care. Edinburgh: Churchill Livingstone 1978.

20. Fung KY, Luginaah IN, Gorey KM: Impact of air pollution on hospital admissions in Southwestern Ontario, Canada: Generating hypotheses in sentinel high-exposure places. Environ Health 2007, 6:18

21. Migliaretti G, Cavallo F: Urban air pollution and asthma in children. Pediatr Pulmonol 2004, 38:198-203.

22. Jensen-Fangel S, Mohey $R$, Johnsen SP, Andersen PL, Sorensen HT, Ostergaard L: Gender differences in hospitalization rates for respiratory tract infections in Danish youth. Scand J Infect Dis 2004, 36:31-6. 
23. Schnabel E, Sausenthaler S, Liese J, Herbarth O, Borte M, Schaaf B, Krämer U, von Berg A, Wichmann HE, Heinrich J: Hospital admission in children up to the age of 2 years. Eur J Pediatr 2009, 168:925-31.

24. Boyd M, Lasserson TJ, McKean MC, Gibson PG, Ducharme FM, Haby M: Interventions for educating children who are at risk of asthma-related emergency department attendance. Cochrane Database of Systematic Reviews 2009, 2: CD001290.

25. British Thoracic Society Standards of Care Committee: BTS statement on criteria for specialist referral, admission, discharge and follow-up for adults with respiratory disease. Thorax 2008, 63:11-i16.

\section{Pre-publication history}

The pre-publication history for this paper can be accessed here: http://www.biomedcentral.com/1471-2296/11/76/prepub

doi:10.1186/1471-2296-11-76

Cite this article as: Uijen et al:: Low hospital admission rates for respiratory diseases in children. BMC Family Practice 2010 11:76.

\section{Submit your next manuscript to BioMed Central} and take full advantage of:

- Convenient online submission

- Thorough peer review

- No space constraints or color figure charges

- Immediate publication on acceptance

- Inclusion in PubMed, CAS, Scopus and Google Scholar

- Research which is freely available for redistribution

Submit your manuscript at www.biomedcentral.com/submit 